\title{
Long-term survival after repair of atrioventricular septal defect
}

\author{
Tjark Ebels, ${ }^{1}$ J. William Gaynor ${ }^{2}$ \\ ${ }^{1}$ Thoraxcentrum, Academisch Ziekenhuis Groningen, Groningen, The Netherlands; ${ }^{2}$ Pediatric Cardiac Surgery, \\ The Children's Hospital of Philadelphia, Pennsylvania, USA
}

T HE TWO PAPERS PUBLISHED IN THIS ISSUE, BY the ladies Frid and Dunlop, along with their respective colleagues in Sweden and Northern Ireland, on long-term survival after repair of atrioventricular septal defect mark the accomplishments in the last decades of dealing with this anomaly. ${ }^{1,2}$ Additionally, these papers demonstrate the value of follow-up studies being long term in the evolution of paediatric cardiac surgery. It is the feedback provided by these long-term studies that should effectively influence our surgical handling in order to optimise treatment. The other essential element in both papers is that all patients born with atrioventricular septal defect are included, instead of reporting only patients that have been operated. The information on patients not undergoing surgery upon is crucial in completing the picture painted to depict the fate of patients born with atrioventricular septal defect.

The monumental Swedish paper deals with no less than all 801 patients with atrioventricular septal defect and shunting at both atrial and ventricular levels, born in that country from 1973 through 1997. As far as we are aware, this is the largest follow-up study in world history. These 801 patients were subdivided into a group of 47 patients with restrictive interventricular shunting, and 754 patients with no restriction to shunting at the ventricular level. This latter group was divided into a group of 502 patients with an isolated defect, and a group of 247 patients with a "complex" defect, by which they mean having additional anomalies other than arterial duct, oval fossa or extra ventricular septal defect. The study from Northern Ireland deals with 106 patients

Correspondence to: Prof. Dr Tjark Ebels MD, Chief, Thoraxcentrum, Academisch Ziekenhuis Groningen, PO Box 30.001, 9700 RB Groningen, The Netherlands. Tel: +31503613238; Fax: +3150361 1347; E-mail: T.Ebels@thorax.azg.nl

Accepted for publication 19 November 2003 born with atrioventricular septal defect in that area over the 9-year period from 1990 through 1998. These authors also distinguish between restrictive and non-restrictive interventricular shunting, using the value of a pressure difference between the ventricle of $30 \mathrm{mmHg}$ as the cut-off point.

This division into subgroups depending on the velocity of flow, or the calculated pressure gradient, of the interventricular shunt has some appeal from a physiological standpoint, because the physiology of patients with restriction to flow is different, and thus so is their presentation. This difference in physiology prompted Weintraub and co-workers ${ }^{3}$ to identify this group as being "intermediate" in the spectrum of hearts with deficient atrioventricular septation. Whether or not this group is given a special name such as "intermediate", separating this group has its drawbacks. Having sequestered them, the composition of the so-called "complete" group, in its turn, is influenced by their absence. Although this study is exceedingly interesting for this reason, it is somewhat difficult to compare the results to other series. The other drawback, however, of sequestering this group is the use of the term "intermediate" for its description. Various definitions exist for "intermediate" types, and also for types called "transistional", so that there is considerable confusion in the literature. ${ }^{4,5}$ The confusion is such that the "intermediate" group defined by one set of investigators may well be dissimilar to that used by others. Indeed, at least five different concepts of an "intermediate form" exist, of which restriction to interventricular shunting is only one. The unfortunate aspect of this particular definition is that the gradient is not only dependent on the size of the interventricular communication. The gradient is also dependent on other haemodynamic variables, such as the absolute ventricular pressures and the right ventricular afterload. 
Wakai and Edwards in 1958 initially defined the intermediate type of lesions on the basis that "a narrow bridge of valvular tissue in the midline joins the anterior half of each of the two cleft atrioventricular valvular leaflets with their respective posterior halves just above the ventricular septum". ${ }^{6}$ Brandt and colleagues, ${ }^{7} 14$ years later, simplified Wakai's definition to "the intermediate form (with small interventricular component)...", thus distinguishing it from the complete form of lesions with a large interventricular communication, and from the partial form with only an atrial communication. Bharati and colleagues, ${ }^{8}$ however, argued that the intermediate group of lesions was unified by “...no bare area on the crest of the ventricular septum. Instead, various forms of valvular tissue cover the summit of the ventricular septum...". They then, and subsequently, divided this small group of hearts into five subsets (!) depending on the precise disposition of the leaflets of the atrioventricular valve. Finally, Draulans-Noë and co-workers used the presence of "...a wide gap and long connecting tongue..." for their definition of the intermediate group of lesions.?

The drawback of the Swedish study is that no data on causes of death are available, since it is an observational study on a population level, providing no operative data. It is not possible, therefore, to make inferences on the risk of anatomical disposition and surgical management. The Northern Irish paper in contrast, does give the data lacking in the Swedish paper, presumably because it encompasses a shorter and more recent inclusion period. The observation in the paper of Dunlop and colleagues ${ }^{2}$ that patients without Down's syndrome have a worse survival is in keeping with our personal experiences, but not entirely consistent in the literature, and not with the results presented by Frid and her associates. ${ }^{1}$ The reason for the latter result is probably the very long inclusion period where strategies for treatment must have varied considerably. Factors explaining the difference in mortality in the Swedish experience are higher prevalence of obstruction in the left ventricular outflow tract, unbalanced ventricles, and preoperative left atrioventricular valvar regurgitation. Anatomical detail explaining the worse valvar function in the chromosomally normal patients is mentioned in the discussion, a smaller mural leaflet being held accountable. It is unclear, however, how the size of the mural leaflet was measured in this study, and no data are given concerning quantification.

Both papers provide strong evidence that early complete repair of "isolated" atrioventricular septal defect, particularly those with an unrestrictive ventricular component, is associated with improved early, and probably late, outcomes. In the current era, we see virtually no role for palliative procedures in these patients, except for patients with "complex" lesions complicated by major associated anomalies in which strategies for treatment must be individualised. It is interesting that, in the experience reported from Northern Ireland, the incidence of late valvar regurgitation is increased in patients with only an atrial component. Since both papers lack surgical detail, nonetheless, inferences on the interaction between anatomy and surgery are impossible.

It cannot be a coincidence that dramatic improvements in mortality happened in Sweden after the centralisation of congenital cardiac surgery in that country achieved in 1993. Keeping the recent recommendations on "Optimal structure of a congenital heart surgery department in Europe" 10 in mind, this observation should be a stimulus for governments to take their responsibilities, and follow the Swedish example. There is ample evidence that results are dependent on size, structure and organisation of departments for congenital cardiac surgery. The only reason most governments are not taking their responsibility may well have to do with the proximity of the political horizon, decisions being determined by the next elections, along with resistance from the professionals themselves, who may have vested reasons to oppose change.

In conclusion, both papers provide a wealth of information to give us further insight into the treatment of atrioventricular septal defect with common atrioventricular junction. Both authors are to be applauded for publishing data that is not limited to surgical patients, nor to favourable subgroups. Further study into the anatomy of the left atrioventricular valve, and correlations with surgical strategies, will lead to further progress in dealing with these patients. Some other problems, such as complex additional anomalies, will continue to give difficulties when seeking to define the optimal surgical strategies.

\section{References}

1. Frid C, Björkhem G, Jonzon A, Sunnegårdh J, Annerén G, Lundell B. Long-term survival in children with atrioventricular septal defect and common atrioventricular valvar orifice in Sweden. Cardiol Young 2004; 14: 24-31

2. Dunlop KA, Mulholland HC, Casey FA, Craig B, Gladstone DJ. A ten year review of atrioventricular septal defects. Cardiol Young 2004; 14: 15-23

3. Weintraub RG, Brawn WJ, Venables AW, Mee RBB. Two-patch repair of complete atrioventricular septal defect in the first year of life: results and sequential assessment of atrioventricular valve function. J Thorac Cardiovasc Surg 1990; 90: 320-326.

4. Ebels T, Anderson RH, Devine WA, Debich DE, Penkoske PA, Zuberbuhler JR. Anomalies of the left atrioventricular valve and related ventricular septal morphology in atrioventricular septal defects. J Thorac Cardiovasc Surg 1990; 99: 299-307.

5. Ebels T, Anderson RH. The concept and definition of an "intermediate" form of atrioventricular septal defect. J Thorac Cardiovasc Surg 1991; 102: 799-800.

6. Wakai CS, Edwards JE. Pathologic study of persistent common atrioventricular canal. Am Heart J 1958; 56: 779-794. 
7. Brandt PWT, Clarkson PM, Neutze JM, Barratt-Boyes BG. Left ventricular cineangiography in endocardial cushion defect: persistent common atrioventricular canal. Australas Radiol 1972; 16: 367-376.

8. Bharati S, Lev M, Mcallister HA, Kirklin JW. Surgical anatomy of the atrioventricular valve in the intermediate type of common atrioventricular orifice. J Thorac Cardiovasc Surg 1980; 79: 884-889.
9. Draulans-Noë HAY, Wenink ACG, Quaegebeur J. Single papillary muscle ("parachute valve") and double-orifice left ventricle in atrioventricular septal defect. Pediatr Cardiol 1984; 11: 29-35.

10. Daenen W, Lacour-Gayet F, Aberg T. Optimal structure of a congenital heart surgery department in Europe by EACTS congenital heart disease committee. Eur J Cardiothorac Surg 2003; 24: 343-351. 